\title{
Differences between Students' Linguistic Knowledge and Text Production Ability: A Case of the Use of Cohesion as a Resource of Texture in Academic Writing
}

\author{
Zulfiqar Ahmad $^{1}$ \\ ${ }^{1}$ ELI, University of Jeddah, Saudi Arabia \\ Correspondence: Zulfiqar Ahmad, ELI, University of Jeddah, Saudi Arabia. E-mail: zulfiqar16c@ hotmail.com
}

Received: July 22, 2019

Accepted: August 13, 2019 Online Published: August 26, 2019

doi:10.5430/wjel.v9n2p55

URL: https://doi.org/10.5430/wjel.v9n2p55

\begin{abstract}
Assuming cohesion as a non-structural resource of texture in text, the present study analyzed students' academic essays to establish the role of cohesion in creating text. A survey was also conducted to gauge students' beliefs about their ability to use cohesive devices in writing. The results of the text analysis and the survey were then used to identify differences between students' linguistic knowledge and their actual use of the cohesion devices. The results revealed statistically significant relationships between the textual variables of cohesion to the extent that the sample texts had visibly dense texture. The results of the survey variables were also found to be statistically significant. In addition, there were gaps in students' understanding of the concept of cohesive devices and their actual use in the texts. The study recommends explicit teaching of cohesive devices rather than as grammatical entities as well as training in expanding the lexical base of the students to help them achieve discourse competence appropriate to the expectations of the academic discourse community.
\end{abstract}

Keywords: academic writing, cohesion, student perceptions, text, texture

\section{Introduction}

A text in text linguistics perspectives is a conglomeration of communication systems and can be assumed a "semantic unit" with focus on meaning rather than on form (Halliday and Hasan, 1976 p.1-2). In other words, a text is a "communicative language event in a context" (Beaugrande and Dressler, 1981 p.63). Following Shaozeng (1995) in Shen (2012) that "context determines text and text reflects context", a configuration of the non-structural and semantic resources of text formation which lend the text its text-forming property i.e. texture, is essential for the realization of any stretch of language use as a communicative event. Cohesion being a non-structural property of text involves relationships between different items of a text in a manner that the meaning is only recoverable when identified with some other linguistic entity in the text. This entails that there are elements in the text which cannot be understood except by recourse to some other element in the text. However, it is the relation between the elements or items and not the item itself that helps in the interpretation of the text, and this item dependency in regard to text interpretation is the key to understanding the concept of cohesion (Halliday and Hasan, 1976). The notion of cohesion is, in fact, premised on the notion of presupposition which establishes an assumed relationship between the addressor and the addressee, and when this relation exists, a cohesive tie is created between them. Presupposition is realized at three different levels: the semantic, the grammatical, and the lexical. At the semantic level, cohesion is derived from the meaning of the message that underlies the text; at the grammatical level, cohesion relates to the structural functions that words have when they configure in a string of relationship in sentence or text; cohesion at the lexical level pertains to the denotational meaning of the individual words (Christiansen, 2011 p.19).

\section{Review of Literature}

\subsection{Cohesion as a Theoretical Concept}

Cohesion studies which initially began with investigating non-structural resources in the creation of text gradually evolved to explore the semanticity of cohesive ties and their significance in discourse structure. Halliday and Matthiessen (2004 p.532) refer to the semantic and contextual resources which are outside the domain of the lexicogrammar but contribute to the creation and interpretation of the text. Martin $(1992,2001)$ interprets cohesion from the perspective of discourse semantics. He seems to be inspired by stratificational linguists, and thereby Published by Sciedu Press 
introduces his own taxonomy of cohesive relations different from Halliday and Hasan's (1976) reference, substitution, ellipsis, conjunction, and lexical cohesion. For him, cohesion originates from a system of discourse semantics but is supra lexicogrammatical in its function with its own metafunctions. He reworked Halliday's non-structural features considering them semantic systems about discourse structure, and proposed identification, negotiation, conjunction, and ideation as sources of cohesion in discourse. Hoey (1991, p.10) who argues that "the study of the greater part of cohesion is the study of lexis, and the study of cohesion in text is, to a considerable degree, the study of patterns of lexis in text". He postulates that both text cohesion and coherence are established through the lexical patterning of individual words with each other. To this end, he introduces the concept of a bond which is the above-average occurrence of lexical ties between two sentences realized through reiteration such as repetition, paraphrase, and referring expressions.

Cohesion operates at both the intrasentence and the intersentence levels. Cohesion at the former level is less noticeable in the presence of grammatical structures (Beaugrande and Dressler, 1981; Christiansen, 2011; Halliday and Hasan, 1976). However, the sentence as the highest unit of grammatical structure may use pronominalization to express intra-sentence cohesion. Hoey (1991), on the other hand, postulates that intrasentence cohesion should be understood as existing not within sentence but among clauses or clause complexes. Nevertheless, it is the intersentence cohesion that is significant because that represents "the variable aspects of cohesion, distinguishing one text from another" (Halliday and Hassan, 1976 p.9).

\subsection{Cohesion and English Language Teaching (ELT)}

McCarthy (1991) and Hoey (1991) in Yao (2013) argue that discourse analysis can be very effective in language pedagogy because of its explicit and implicit focus on naturally occurring language above the level of sentence. Following discourse analysis from this perspective, the concept of cohesion in ELT seems to be based on the assumptions that "language is realized, first and foremost, in a text"; language users have "to make sense" of texts and produce them; and the task of the language teacher is to help his students "engage with texts" (Thornbury, 2005 p.6). McCarthy (1991 p.147) corroborates these assumptions by suggesting that the language teachers should know "how different texts are organized and how to realize the process of creating written texts" in order to develop authentic instructional material for the classroom. Cohesion being one of the defining properties of text has, therefore, prime importance both in the process of discourse development and the creation of text as a final product. This entails that the notion of cohesion is associated with the linguistic competence of the student writers especially in academic context when the assessment of the final product is the "only measurements to verify students' academic achievement" (Hinkel, 2001 p.123). Linguistic competence which has its origins in Hymes' (1972) concept of communicative competence, thus, carries vital significance and far reaching implications for teaching and learning of academic writing.

Zamel (1983 p.165) believes in the effectiveness of teaching cohesive devices for their potential to "turn separate clauses, sentences, and paragraphs into connected prose, signaling the relationships between ideas, and making obvious the thread of meaning the writer is trying to communicate". Yao (2013) believes that good understanding of cohesive devices can help learners to improve their reading comprehension since it is essential for them to identify, for instance, the referents without looking back to the passage, especially in the case of pronouns and demonstratives. This also develops their sense of the text pattern and subsequent analysis which, according to Hoey (2001), facilitate reading and writing skills for those students trained in rhetorical traditions other than English. According to Dooley and Levinsohn (2001 p.6):

"Cohesion is likewise important to the text analyst. When you analyze discourse, especially without a native speaker's intuitions of language and culture, on what do you base your judgment of the text's coherence? On what basis can you construct a mental representation for it, whether internal or external? While cohesion does not provide the only answer (native speakers and the study of culture should help), it can certainly provide important evidence".

Explicit teaching of cohesive devices (McCarthy: 1991) can, thus, enable students to familiarize themselves with a range of textual patterns in the target language ultimately creating a meaningfully unified text. From the perspective of L2 writing pedagogy, Halliday and Hasan's (1976) theory of cohesion has led to significant developments in English-language teaching (ELT). Their taxonomy of cohesive devices based on reference, substitution, ellipsis, conjunction and lexical items such as reiteration and collocations are instrumental in creating cohesion in text. Hinkel (2001) observes that the focus of cohesive devices in L2 writing is on use and meaning, while in reading issues related to logical progression of ideas and text organization are targeted. In Halliday and Hasan 's (1976) view, text cohesion in turn leads to greater text coherence. Tadros (1994) in Hinkel (2001) has reported the use of enumerative nouns such as those of categorization and division (class, type, category, issue, matter, problem), for instance, as one of higher frequency in academic writing. Several textbooks on academic writing for L2 students contain an explicit material on 
cohesive devices mostly dealing with coordinators, subordinators, and transition signal with the aim to enable L2 student writers produce cohesive texts comprehensible to the native speaker readers (Reid, 1993).

\subsection{Cohesion and Writing Quality}

Although controversial from empirical research point of view, the concept of cohesion is usually thought of as a determiner of writing quality. Research studies by Witte and Faigley (1981) and McCulley's (1985) found that high grade essays had a higher frequency and use of cohesive devices as compared with the low grade essays. Hinkel (2001 p.128), on the other hand, found that cohesive devices particularly, transition signals do not contribute to the smooth progression of text: "the uses of sentence transitions in L2 texts do not necessarily mark a contextualized flow of information when sentence transitions are intended to identify the meaningful relationship of ideas in discourse". She suggests that the teachers of academic writing should adopt a focus in order to add to the "learners' accessible repertoire of grammatical structures and lexis" - features of cohesion integral to the production of appropriate and acceptable academic writing. One way of achieving this could be to allow the learners have their voice heard in regard to the course design and evaluation whereby they would be able to contribute to the language learning process. A study of students' perceptions can, therefore, yield valuable information in regard to their learning needs, preferences, quality of the course design and delivery etc.

\section{Aims and Significance of the Study}

Despite the availability of cohesion analysis from multiple dimensions such as frequency counts, density, text quality etc., there is relative dearth of textual analysis which ascertain the role of cohesion in creating texture. Similarly, an analysis of students' perceptions about the use of cohesion in academic writing also seems an under-researched area. This study proposes to address these gaps by studying cohesion as a text-forming resource in undergraduate writing and collating the analysis with students' beliefs about the topic. The findings are likely to provide some useful insights to those involved in academic writing pedagogy, course design, and research.

\section{Methods}

The study adopted mixed-methods and triangulation to find out the role of cohesion in creating texture in academic writing and collated the textual evidence with students' perceptions to further validate the findings of the textual analysis. $\mathrm{N}=30$ of the undergraduate students' academic (argumentative) essays were collected from the Yanbu English Language Institute, Saudi Arabia (YELI). Cohesion analysis was based on Halliday and Hasan's (1976) framework. For the purpose of analysis, the notion of texture was operationalized to investigate the presence of appropriately used cohesive devices which created association between the presupposed and the presupposing items intersententially via grammatical, lexical or semantic resources irrespective of the text quality. Appropriate use of cohesion was defined to be the presence of ties which had a clear referent in the text. The notion of inappropriate use was based on those cohesive relations which disrupted text cohesion either being ambiguous or too remote in the text to be meaningfully retrievable (Cox et al.1991). Following Halliday and Hasan (1976), sentence unit (SU) analysis was used to identify the presence of referential (R), conjunctive (C) and lexical cohesion (L). Substitution and Ellipsis were excluded from the analysis due to their anticipated low frequency in academic writing (McCarthy, 1991). Instances of appropriate and inappropriate use in each SU were coded as belonging to R, C, and L and their subcategories. Similarly, the survey $(\mathrm{N}=60)$ with six items on it was completed by the undergraduate students at YELI. The survey items (can do statements) were created to elicit students' response about R, C, and L cohesion; however, a little change in the terminology was made to facilitate the participants. For instance, the terms 'coordinator' and 'subordinator' were used instead of the 'conjunctives' because the students had been taught as such. The class teachers were requested to help the students with completing the survey if they had any problems identifying the correct term for cohesion devices.

\section{Results}

SPSS was used to obtain sum, percentage, mean, median, standard deviation, and interquartile range scores as well as non-parametric correlation analysis to find out statistically significant associations between the variables of the sample texts and the survey.

\subsection{Results for Cohesion Analysis}

The subsections below present results obtained from the cohesion analysis of the sample texts:

\subsubsection{Descriptive Statistics for Appropriate (A) and Inappropriate (IA) Reference}

Descriptive statistics revealed that out of $n=1954 \mathrm{CDs}$ in the entire corpus, $\mathrm{R}$ was the second most frequent device after $\mathrm{L}$ for appropriate use and the most common in terms of inappropriate use. Table T-1 shows that appropriate 
personal reference (AR1) $(M=12.20 ; S D=8.138 ; M d n=10.50 ; I Q R=12)$ was the most commonly used reference type appropriately employed by students for 366 times. On the other hand, the inappropriate personal reference (IAR1) use $(M=2.73 ; S D=1.818 ; M d n=3.00 ; I Q R=3)$ which occurred 82 times in the texts indicated that some students had problems in using the personal reference either in terms of case, number, or gender while referring back to the antecedent. Appropriate demonstrative reference (AR2) $(M=6.13 ; S D=3.350 ; M d n=6.00 ; I Q R=5)$ was used at 184 instances in the texts while the inappropriate (IAR2) $(M=1.10 ; S D=1.373 ; M d n=.50 ; I Q R=2)$ was used 33 times only. These results indicated that students were mostly comfortable while using R2; however, some of them experienced issues with the accurate use which suggested that they could not handle matters of specificity or proximity while referring back to the presupposed item in the text. AR3 $(M=1.57 ; S D=1.455 ; M d n=1.00 ; \operatorname{IQR}=$ 3 ) was identified 47 times whereas, no evidence of IAR3 could be found in the texts.

Table 1. RQ1. Descriptive Statistics for A \& IA Reference

\begin{tabular}{|c|c|c|c|c|c|c|}
\hline $\mathrm{N}=30$ & AR1 & IAR1 & AR2 & IAR2 & AR3A & IAR3 \\
\hline Mean & 12.20 & 2.73 & 6.13 & 1.10 & 1.57 & Constant \\
\hline SD & 8.138 & 1.818 & 3.350 & 1.373 & 1.455 & \\
\hline Median & 10.50 & 3.00 & 6.00 & .50 & 1.00 & \\
\hline IQR & 12 & 3 & 5 & 2 & 3 & \\
\hline Sum & 366 & 82 & 184 & 33 & 47 & \\
\hline$\%($ from $n=1954)$ & 18.73 & 4.1 & 9.41 & 1.68 & 2.40 & \\
\hline
\end{tabular}

\subsubsection{Correlation Analysis of A and IA Reference}

The correlations of the total reference devices (TR) were tested against Appropriate Reference (AR) and Inappropriate Reference (IAR) devices by Kendall's tau-b. The results revealed positive significant relationship of TR with AR and IAR, and between AR and IAR. TR had a very strong positive significant correlation with AR $r_{t}$

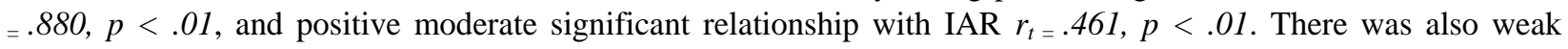
positive significant relationship between AR and IAR $r_{t=} .311, p<.05$. The results suggested that most students used AR which increased with an increase in TR; However, the increase in IAR in relation to TR was not as frequent as that of the AR with TR. The results also indicated that there were moderate chances of an increase in IAR with an increase in AR.

\subsubsection{Descriptive Statistics for A and IA Conjunctions}

From an overall use of 247 conjunctives in the corpus, 229 were appropriately used by the students. Table T- 2 shows that appropriate adversative conjunctives (AC2) were the most preferred Conjunction among the students followed by appropriate causal (C3A), temporal (AC4), and additive (AC1) conjunctives respectively. $\mathrm{AC} 1(M=1.60 ; S D=1.812$; $M d n=1.00 ; I Q R=3)$ was employed 48 times in the texts as opposed to IAC1 $(M=.23 ; S D=.898 ; M d n=.00 ; I Q R=$ 0 ) had a low presence on only 7 occasions. $\operatorname{AC2}(M=2.33 ; S D=1.516 ; M d n=2.00 ; I Q R=2)$, on the other hand, was the most commonly used conjunctive in students' essays which they used 70 times. Again, as with IAC1, IAC2 was also very sparse and only 7 inappropriate items could be identified in the sample. AC3 $(M=1.87 ; S D=1.833 ; M d n=2.00$; $I Q R=1)$ and AC4 $(M=1.83 ; S D=1.633 ; \mathrm{Med}=1.00 ; I Q R=2)$ were used with the minimal difference of 1 item only i.e. 56 and 55 respectively. IAC 3 had only 3 items whereas, no item was found in the data for IAC4.

Table 2. Descriptive statistics for Conjunction

\begin{tabular}{lllllllll}
\hline $\mathrm{N}=30$ & AC1 & IAC1 & AC2 & IAC2 & AC3 & IAC3 & AC4 & IAC4 \\
\hline Mean & 1.60 & .23 & 2.33 & .23 & 1.87 & .10 & 1.83 & .03 \\
Std. Deviation & 1.812 & .898 & 1.516 & .568 & 1.833 & .305 & 1.663 & .183 \\
Median & 1.00 & .00 & 2.00 & .00 & 2.00 & .00 & 1.00 & .00 \\
IQR & 3 & 0 & 2 & 0 & 1 & 0 & 2 & 0 \\
Sum & 48 & 7 & 70 & 7 & 56 & 3 & 55 & 1 \\
$\%(\mathrm{n}=1954)$ & 2.45 & 0.35 & 3.58 & 0.35 & 2.86 & & 2.81 & \\
\hline
\end{tabular}

\subsubsection{Correlation Analysis for A and IA Conjunctions}

The correlation of the total Conjunction (TC) with appropriate Conjunctions (AC) and inappropriate Conjunctions (IAC) was computed using Kendall's tau_b which revealed a very strong positive significant relationship with AC $r_{t}$ $=.899, \mathrm{p}<.01$. No significant relationship was found between TC and IAC, and AC and IAC. The results indicated 
that there were very high chances of the students making appropriate choice in regard to the use of conjunctive devices in their texts.

\subsubsection{Descriptive Statistics for A and IA Lexical Cohesion}

Lexical cohesion formed almost half of the CDs in students' writing. Following Al-Jabouri (1984), I analyzed repetition (L1) as a cohesive device by counting not only instance of the repetition of the same lexical item but also identified, wherever evident, the presence of morphological and chunk-level repetition. All subcategories of repetition were, however, computed as belonging to L1 without any further classification into their respective subclasses.. Table T-3 unfolds that AL1 $(M=24.20 ; S D=8.837 ; M d n=22.00 ; I Q R=14)$ with 726 items found the highest preference among the student writers. These results made AL1 the most prominent feature of students' texts especially in view of the existence of only 15 IAL1 items $(M=.50 ; S D=1.225 ; M d n=.00 ; I Q R=5)$. Other types of appropriate Lexical cohesion is visible in the texts but to a very limited extent. Appropriate synonyms (AL2) $(M=1.57 ; S D=1.813 ; M d n=1.00 ; ; I Q R=3)$; appropriate superordinates (AL3) $(M=1.73 ; S D=1.68 ; M d n=1.50$; $I Q R=3$ ); appropriate General word (AL4) $(M=2.33 ; S D=2.187 ; M d n=2.00 ; I Q R=2)$ and appropriate collocations (AL5) $(M=1.57 ; S D=2.239 ; M d n=1.00 ; I Q R=2)$ comprised of 47, 52, 70 and 47 lexical items respectively. The inappropriate use of these types of Lexical cohesion, on the other hand, was not very frequent. The results revealed that despite the overwhelming use of L1A which indicated extremely low levels of the lexical range of the students, the occurrence of inappropriate use was not common.

Table 3. Descriptive statistics for Lexical cohesion

\begin{tabular}{lllllllllll}
\hline $\mathrm{N}=30$ & AL1 & IAL1 & AL2 & IAL2 & AL3 & IAL3 & AL4 & IAL4 & AL5 & IAL5 \\
\hline Mean & 24.20 & .50 & 1.57 & .10 & 1.73 & .10 & 2.33 & .07 & 1.57 & Constant \\
Std. Deviation & 8.837 & 1.225 & 1.813 & .403 & 1.680 & .403 & 2.187 & .254 & 2.239 & \\
Median & 22.00 & .00 & 1.00 & .00 & 1.50 & .00 & 2.00 & .00 & 1.00 & \\
IQR & 14 & 5 & 3 & 0 & 3 & 0 & 2 & 0 & 2 & \\
Sum & 726 & 15 & 47 & 3 & 52 & 3 & 70 & 2 & 47 & \\
$\%(\mathrm{n}=1954)$ & 37.15 & 2.40 & 2.40 & & 2.66 & & 3.58 & & 2.40 & \\
\hline
\end{tabular}

\subsubsection{Correlation Analysis for A and IA Lexical Cohesion}

Kendall's tau_b was applied to test the correlation of the total lexical cohesion (TL) with appropriately used lexical devices (AL) and inappropriately used ones (IAL). The test showed very strong positive significant correlation

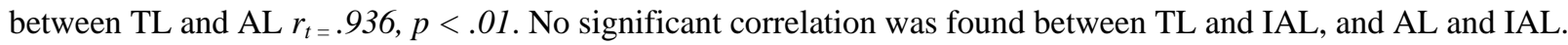
The results suggested that there were highly strong chances of the students being able to use lexical cohesion in their texts appropriately.

\subsection{Results of the Survey}

Students' survey results mostly showed disagreed or neutral responses such as IC6 "I can use collocations appropriately." $(M=2.77 ; S D=.789 ; M d n=3.00 ; I Q R=1)$ with $30 \%$ disagreement and $58 \%$ neutral response.

Table T-4 shows the descriptive statistics for each of the survey statement.

Table 4. Descriptive analysis of the survey

\begin{tabular}{lllllll}
\hline & \multicolumn{1}{c}{ Survey items } & Code & \multicolumn{3}{c}{ Stusents' Perceptions (N = 60) } \\
\cline { 5 - 7 } & & & M & SD & Mdn & IQR \\
\hline 1 & I can use personal reference appropriately. & IC1 & 2.47 & .821 & 2.00 & 1 \\
2 & I can use demonstrative and comparative reference & IC2 & 2.60 & .848 & 2.50 & 1 \\
& appropriately. & & & & & \\
3 & I can use coordinators appropriately. & IC3 & 2.77 & .789 & 3.00 & 1 \\
4 & I can use subordinators appropriately & IC4 & 2.40 & .848 & 2.00 & 1 \\
5 & I can use reiteration (repetition, synonyms, superordinates, & IC5 & 2.40 & .848 & 2.00 & 1 \\
& general word) appropriately. & & & & & \\
6 & I can use collocations appropriately. & IC6 & 2.77 & .789 & 3.00 & 1 \\
\hline
\end{tabular}




\subsubsection{Correlation Analysis of the Survey}

Spearman rho $\left(\mathrm{r}_{\mathrm{s}}\right)$ for the only strong positive correlation for students' survey found was between IC1 and IC4, $r$ $=.633, p<.01$. whereas, IC3 and IC4, $r_{s}=.540, p<.01$, IC4 and IC2, $r_{s}=.509, p<.01$, IC2 and IC6, $r_{s}=.552, p$ $<.01$ showed moderate positive relationship. The results revealed that there were weak, moderate and strong chances of a perception on a scale being increased with an increase on a similar scale in the corresponding item on the survey.

\section{Discussion}

\subsection{Referential Cohesion}

Personals or pronominals are the most frequently used subcategory in Reference comprising of $18.73 \%$ of appropriate use in the overall corpus. This pattern of pronominal use supports Zhang (2000) but contradicts Mckay (2007) whose study found demonstrative reference higher than pronominal. These results for Reference indicate that the students are mostly able to identify the presupposed item and refer back to it to create co-referential ties that contribute towards cohesion in the texts. The students employed "they/them/their" more often than "he/she/him/her/it" probably because while writing academic essays they chose to move from the general to the specific using plural nouns as their antecedents. There is also significant use of the specific demonstratives "this/these/that/those" and the non-specific demonstrative - the definite article "the" which form 19\% and 11\% respectively of referential devices. This entails that students were quite successful in using notions of proximity and specificity in their writing. These results support Liu and Brain (2005), but contradict Neuner's (1987) findings that the use of demonstratives was a little higher than the definite article. Similarly, some students have successfully used comparative reference which though not highly significant in relation to R1 and R2 shows these students' ability to draw comparisons while at the same time connecting the text with the preceding item or ideas. This appears to give the text not only syntactic variety and complexity but also creates semantic relationships.

Most of the students either disagreed or stayed neutral in response to the survey items which is both collates and contradicts with the results of referential cohesion, for instance. Reference devices being the second most frequently and correctly used devices refute students' stance that they cannot use referential cohesion appropriately while their errors indicate that they have problems in creating coreferential ties either because of referent ambiguity, number or negative transfer. One reason seems to be the teaching of reference devices as grammatical items rather than cohesive entities based on semantic associations. The excerpts from students' essays illustrate the use of referential cohesion:

i. $\quad$ People think that Saudi youth are losing thier cultural Identity. $i$ agree with them.(AR)

ii. So, do not hesitate from playing video games or provide it to your children if you are going to use it carefully as it is full of fun and learn.(IAR)

\subsection{Conjunctive Cohesion}

The lack of training in creating semantic relationships is, however, more prominently revealed in students' beliefs about conjunctive cohesion which was supported by the cohesion analysis of the sample texts. Although the students deny competent use of coordinators (IC3) and subordinators (IC4), their actual use of the conjunctives in the sample texts is mostly appropriate with an extremely limited range though. For the current study, C2 was the most commonly used conjunctive device with $31.17 \%$ use from 247 devices followed by C3 (23.88\%), C4 (22.67\%) and C1 (22.26\%). These figures contradict Mckay (2007) and Hamed (2014) who find C1 to be the most frequently used conjunction in academic writing. However, a deeper analysis reveals some useful features of conjunctive devices as employed by the students in their writing. English language has a repertoire of approximately 80 conjunctives or logical connectors (Asassfeh, et.al., 2013); however, the students of the present study could employ 34 types. Only seven out of these conjunctives (for example, however, but, on the other hand, because, so, in conclusion) were significant; the others were few in number and widely scattered along the texts. Following the notion of form and function, it is evident that students preferred certain types of adversatives to others in order to achieve their discourse objectives. This, however, implies that academic writing pedagogy should explicitly cater for the inclusion of conjunctives, especially the use of adversatives.

The inappropriate use of conjunctions as earlier reported in the results is highly insignificant as compared with the appropriate use (supported by Hamed, 2014) - only 18 out of 247 conjunctives were identified to be misused by the students. This suggests that conjunctions were not seriously challenging for the students. The results for conjunctions bring forth two very interesting findings: First, the very limited use of the additive "and" refutes most other research claims in the Arab context (Hamed, 2014); secondly, following Johns (1980) that around 10\% conjunctive use is Published by Sciedu Press 
typical of the NS texts, these texts with $12.64 \%$ use stand very close to the NS standard. However, the range of conjunctives especially those which have been more frequently used is very narrow, and thereby restricts conjunctive functions to a very few. But it cannot be assumed with certainty that low percentage of conjunctions correlates with writing quality. Since the present study does not propose to study this type of relation, future research in Saudi EFL context can take up such an initiative.

\section{iii. $\quad$ Moreover, they start using some facts and arguement that support their opinion. \\ iv. On the other hand people who supported this type also argue that its only for fun and will not affect the young.}

\subsection{Lexical Cohesion}

As found in research on text cohesion in EFL contexts (McGee, 2009), and specifically the Arab (e.g. Abdul Rahman, 2013), Lexical devices are the most predominantly used items in the sample texts for this study. Students' perceptions about reiteration (IC5) contradict while that about collocation (IC6) support results of the text analysis. The texts reveal heavy dependence on repetition of the same lexical item which point to the limited lexical range of the student writers. Synonyms, Superordinates, and the General word which are features of expert writiers' usage do not figure prominently in students' texts. The examples from the samples show how students used lexical devices in their academic writing:

v. Happiness is the thing that the whole humans are look for. All people are pursuing happiness and only few people can cach it.

vi. $\quad$ the Saudi culture identity (presupposed = culture) is gone time by time spessialy in Saudi youth. (IAL)

vii. they also cliams that saudi youth in the way to improve and devlops thier life by technologies fasion.( The general noun "the way" in is contextually inappropriate and could have been substituted by "an effort/attempt" for clarity of meaning.)

\subsection{Cohesion and Texture in Students' Writing}

Students' perceptions unfold differences in their understanding of cohesion as a text-forming resource and actual performance which indicates that they are either not familiar with cohesion as a source of texture or cohesion as such is not explicitly taught in the writing course design.

It, however, must be taken into account that cohesion provides only a partial explanation of texture in any text or set of texts for there are, according to Halliday and Hasan (1976), two other textual components that contribute to texture namely the intra-sentence structure and the macro structure of discourse. The present study focused only on the use of cohesive devices, and is, therefore, limited in its scope.

The basic premise behind the function of cohesion in creating texture is the use of lexico-grammatical resources to create semantic relationships between different parts of the text so that an interdependence of one item on the other is developed and when this happens not only there is appropriate interpretation of the text but also a continuity in discourse which lends unity to the piece of text or defines it as a text. Following the notion of texture as has been operationalized for this study, cohesion in the texts of the Saudi undergraduate students can be seen as creating texture which mostly depends on Lexical cohesion followed by referential and conjunctive. This is supported by the results which indicate that 1798 out of 1954 (92.01\%) CDs have been appropriately used. In other words, "the type of presupposition that provides texture in the text" (Halliday and Hasan, 1976 p.294) is predominantly identifiable in the texts. The proportion of overused CDs cannot be accounted for minimizing the role of cohesion in the creation of texture; they do, however, diversify the pattern of texture.

Halliday and Hasan (1976 p.296) refer to two types of texture: tight and loose. Tight texture refers to a textual instance where a "dense cluster of cohesive ties" is evident which indicates that "the meaning of the parts are strongly interdependent and that the whole forms a single unity" whereas textual instances where there are a few cohesive ties "perhaps one or two" can be dubbed as loose texture. The texts of the Saudi students, from this perspective have visibly tight or close texture.

For one thing, the students attempted academic genre where they had to respond to a topic statement arguing in favour or against. The genre itself dictates the choice of register and thereby, cohesive devices in this regard (Martin, 2001). Writing, from both SFL and Contrastive Rhetoric Tradition perspectives, is embedded in socio-cultural context. The interaction between the writer and the reader is also very important alongside the lexicogrammatical devices that create the text. This interaction is strengthened by the system of tenor, field, and mode collectively referred to as register (Halliday and Hassan, 1976). In other words, register refers to a pattern of linguistic choices Published by Sciedu Press 
which are dictated by socio-cultural context or preference i.e. genre or a pattern of register choices (Martin, 2001). The argumentative essays, observed from this perspective, reveal a set of register choices that conform to the needs of the target genre. For example, frequent use of the third person pronouns (they, them, their) indicate an attempt to achieve formality and objectivity on the part of the writer which is an essential feature of academic writing (Hinkel, 2003; McCarthy, 1991). Similarly, the appropriate use of conjunctives by establishing ties with the previous information facilitate materialization of several rhetorical or academic functions such as cause and effect, exemplification, comparing and contrasting, supporting or refuting an opinion etc. Lexical devices despite the excessive use of repetition of the same item build the content of the essays. All these lexico-grammatical choices contribute to the creation of register which realizes the formation of texture in students' writing as well as make them compatible with the demands of the genre.

\section{Conclusion}

Nevertheless, as stated earlier, these students' texts do not represent a holistic picture of texture following certain constraints both of the concept and the present research. The former is about the exclusion of the intra-sentence structure and the macro structure of the texts from the study of texture. The latter pertains to some of the research foci that could not be included in the study owing to limitations of time and space. For instance, the relationship of cohesion and texture in and between paragraphs can reveal further insights into the patterns of texture. In addition, a study of the relationship among cohesion, texture, and quality of writing can unfold some interesting findings. These essays were written by novice EFL writers in a specific context who were learning academic writing for higher education and occupational purposes. As such, expecting them to write to expert or the NS level would be fallacious in view of the curricular, academic, institutional, and socio-cultural constraints imposed on them. Their writing should be judged in a realistic framework of the context they are working. However, drawing on the insights from previous and contemporary research, appropriate measures should be taken to facilitate them progress from novice to good, good to proficient, and proficient to expert writers.

\section{References}

Abdul, R. Z. A. (2013). The Use of Cohesive Devices in Descriptive Writing by Omani Student-Teachers. SAGE Open, 1-10.

Al-Jubouri, A. (1984). The role of repetition in Arabic argumentative discourse. In J. Swales \& H. Mustapha (Eds.), English for specific purposes in the Arab world (pp. 99-117). Birmingham, UK: The Language Studies Unit, University of Aston.

Asassfeh, S., Alshboul, S., \& Alshaboul, Y. (2013). Distribution and appropriateness of use of logical connectors I the academic writing of Jordanian English- major undergraduates. Journal of Educational \& Psychological Sciences, 14(3), 12-35.

Christiansen, T. (2011). Cohesion: A discourse perspective, Berlin: Germany, Continuum. https://doi.org/10.3726/978-3-0351-0234-5

Cox, B. E., Shanahan, T., \& Sulzby, E. (1990). Good and poor elementary readers' use of cohesion in writing. Reading Research Quarterly, 25, 47-65. https://doi.org/10.2307/747987

Cox, B. E., Shanahan, T., \& Tinzmann, M. B. (1991). Children's knowledge of organization, cohesion, and voice in written exposition. Research in the Teaching of English, 25(2), 179-218.

De Beaugrande, R. A., \& Dressler, W. U. (1981). Introduction to Text Linguistics. London: UK, Longman. https://doi.org/10.4324/9781315835839

Dooley, R. A., \& Levinsohn, S. H. (2001). Analyzing discourse: A manual of basic concepts. Dallas: SIL International.

Halliday, M. A. K., \& Hasan, R. (1976). Cohesion in English. London: UK, Longman.

Halliday, M. A. K., \& Mathiessen, C. (2004). An introduction to functional grammar. London, UK, Hodder Arnold.

Hamed, M. (2014). Conjunctions in Argumentative Writing of Libyan Tertiary Students English Language Teaching, Canadian Center of Science and Education, 7(3), 108-120. https://doi.org/10.5539/elt.v7n3p108

Hinkel, E. (2001). Matters of cohesion in L2 academic texts. Applied Language Learning, 12(2), 111-132.

Hinkel, E. (2003). Simplicity without elegance: Features of sentences in L1 and L2 academic texts. TESOL Quarterly, 37(2), 275-301. https://doi.org/10.2307/3588505 
Hoey, M. (1991a). Patterns of lexis in text. Oxford: UK, Oxford University Press.

Hymes, D. H. (1972). Toward ethnographies of communication. In P.P. Giglioli (Ed.), Language and social context (pp. 21-44). Harmondsworth: UK, Penguin.

Johns, A. (1980). Cohesion in written business discourse: Some contrasts. The ESP Journal, 1, 35-43. https://doi.org/10.1016/0272-2380(80)90008-6

Khalil, A. (1989). "A Study of Cohesion and Coherence in Arab EFL College Students' Writing". System, 17(3), 359-371. https://doi.org/10.1016/0346-251X(89)90008-0

Liu, M., \& Braine, G. (2005). Cohesive features in argumentative writing produced by Chinese undergraduates. System, 33, 623-636. https://doi.org/10.1016/j.system.2005.02.002

Martin. (2001). Cohesion and texture. In D. Schiffrin, D. Tannen, and H. Hamilton (Eds), The Handbook of discourse analysis. Oxford: UK, Blackwell.

McCarthy, M. (1991). Discourse Analysis for Language Teachers. Cambridge: UK, Cambridge University Press.

McCulley, G. A. (1985). Writing quality, coherence, and cohesion. Research in the Teaching of English, 19, 269-280.

McGee, I. (2009). Traversing the lexical cohesion minefield. ELT Journal, 63, 212-220. https://doi.org/10.1093/elt/ccn040

McKay, S. L. (1992). Teaching English Overseas: An Introduction. Oxford: UK, Oxford University Press.

Neuner, J. L. (1987). Cohesive ties and chains in good and poor freshman essays. Research in the Teaching of English, 17, 215-229.

Shen, L. (2012). Context and text. Theory and Practice in Language Studies, 2(12), 2663-2669. https://doi.org/10.4304/tpls.2.12.2663-2669

Thornbury, S. (2005). Beyond the Sentence: Introducing Discourse Analysis. Oxford: UK, Macmillan Education.

Witte, S., \& Faigley, L. (1981). Coherence, cohesion, and writing ability. College Composition and Communication, 32, 189-204. https://doi.org/10.2307/356693

Yao, C. A. (2013). Nominal classification and verbal nouns in Baïnounk Gubëeher. PhD Thesis. SOAS, University of London. http://eprints.soas.ac.uk/17370

Zamel, V. (1983). The composition processes of advanced ESL students: Six case studies. TESOL Quarterly, 17, 165-187. https://doi.org/10.2307/3586647

Zhang, M., (2000). Cohesive features in exploratory writing of undergraduates in two Chinese universities. RELC Journal, 31, 61-93. https://doi.org/10.1177/003368820003100104 